\title{
Effect of PMR and AGR to Improve Mood States in Beginner Athletes
}

\author{
Eddy Marheni ${ }^{1, *}$, Eko Purnomo ${ }^{1,2}$, Nina Jermaina ${ }^{2}$, Afrizal $\mathbf{S}^{1}$, Vega Soniawan ${ }^{1}$, \\ Rizki Burstiando ${ }^{2,3}$, Faradifta Tirta Ardita ${ }^{1}$ \\ ${ }^{1}$ Faculty of Sports Science, Universitas Negeri Padang, Padang, 25132, West Sumatra, Indonesia \\ ${ }^{2}$ Doctoral Program of Sports Education, School Postgraduates Studies, Universitas Pendidikan Indonesia, \\ Bandung, 40154, West Java, Indonesia \\ ${ }^{3}$ Physical Education, Faculty of Health and Science, Universitas Nusantara PGRI Kediri, Kediri, 64112, East Java, Indonesia
}

Received July 22, 2021; Revised September 17, 2021; Accepted October 17, 2021

\section{Cite This Paper in the following Citation Styles}

(a): [1] Eddy Marheni, Eko Purnomo, Nina Jermaina, Afrizal S, Vega Soniawan, Rizki Burstiando, Faradifta Tirta Ardita , "Effect of PMR and AGR to Improve Mood States in Beginner Athletes," International Journal of Human Movement and Sports Sciences, Vol. 9, No. 6, pp. 1254 - 1261, 2021. DOI: 10.13189/saj.2021.090620.

(b): Eddy Marheni, Eko Purnomo, Nina Jermaina, Afrizal S, Vega Soniawan, Rizki Burstiando, Faradifta Tirta Ardita (2021). Effect of PMR and AGR to Improve Mood States in Beginner Athletes. International Journal of Human Movement and Sports Sciences, 9(6), 1254 - 1261. DOI: 10.13189/saj.2021.090620.

Copyright $\bigcirc 2021$ by authors, all rights reserved. Authors agree that this article remains permanently open access under the terms of the Creative Commons Attribution License 4.0 International License

\begin{abstract}
The purpose of this study was to determine the effect of the Progressive Muscle Relaxation (PMR) program and also Autogenic Relaxation (AGR) on improving mood in high jump beginners. The design in this study is a pretest-posttest control group design, which is a design that has a pretest before being given treatment. The participants used were high jump beginner athletes with an average age of 17-20 years. The total participants were 38 people. Then they are randomized and divided into 2 groups (PMR and AGR). A total of 20 samples were in the PMR group and 18 samples were in the AGR group. The results of the study are based on the calculation of independent samples test. It is known that the value of Sig (2-tailed) is $0.000<0.05$, thus it can be concluded that there is a significant (significant) difference in effectiveness between the use of the PMR method and AGR to improve the mood states of athletes, high jump beginners. The results of the study stated that the significance value (Sig) on Levene's Test for Equality of Variances was 0.530 or $>0.05$. So, it can be concluded that the variance of the $\mathrm{N}-$ Gain data (\%) for the PMR and AGR groups is the same (no difference). It was further explained that the value of the independent samples test of significance (Sig) (2-tailed) was 0.000 or $<0.05$. Thus, there is a significant (significant) effectiveness difference between the use of the PMR and AGR methods to improve the mood states of novice high jump athletes. Further research is recommended to
\end{abstract}

implement PMR and AGR programs with a longer period of time and allow them to be applied to individual sports and team sports to be able to determine the level of effectiveness.

Keywords Mood States, PMR and AGR

\section{Introduction}

Mood is a condition in which a good or bad mood is influenced by the interaction between individuals, so that it can make the individual happy, afraid, anxious, happy, even tired and can even result in prolonged stress and depression [1]. Boredom and boredom in doing daily exercise make athletes feel stressed, depressed and tired faster, resulting in a lack of enthusiasm for athletes in training. As a result, there is a decrease in motivation and emotions to practice, so that in the end they don't want to be an athlete [2]. Lack of daily competition tests and monotonous training procedures are the cause of increased burnout, boredom, and can increase overtraining, leading to injury as well as stress [3]. Mood disorders are one of the most common disorders and can affect human health [4].

Mood is different from emotion (it is temporary). Emotions are constantly responding to the various ideas 
that exist as well as the social circumstances that we face throughout the day. Meanwhile, mood is a continuation of emotion behavior that lasts for some time, a few hours, even a few days [5]. The ups and downs of mood not only damage the individual concerned, but also cause unusual tensions in other people around him. It was further explained that mood (mood) is a form of emotional state [6]. The mood state of each individual can take place with different intensity and duration [7]. The difference between emergence and emotion is that they are often non-specific, not strong, and not always caused by a particular stimulus or event. Emotional instability and a person's mood will result in stress on himself, and even mental decline can affect other psychological functions and will ultimately affect achievement [8].

The psycho-physical theory of totality developed among experts and realized that people who experience mental disorders, because they feel difficult, anxious or hesitant to face something, actually affect their physical condition [9]. In sports activities, to achieve high achievements, certain psychological aspects are needed; For example, in archery, athletes must be able to focus well, calmly, confidently, and with high concentration despite noise and wind disturbances.

The highest achievement of an athlete is the ability to win a competition. But achieving this requires practice, hard work, hard work and prayer [10]. The quality of the trainers can be said to be very good; this can be seen from the establishment and design of training systems and training plans that are carried out continuously and correctly. Besides that, trainers and assistant trainers who excel in improving the quality of trainers have also been followed. trainer, as evidenced by a certificate. One of the functions of mood in athletes is to create enthusiasm in training. Because if the athlete's mood is not good then the mood will not make the spirit in training. This mood itself has two forms, namely positive and negative. Mood states can predict the success of an athlete's performance, namely the influence of a very high positive mood. However, this negative mood greatly affects the mental readiness of athletes. For example, during exercise the athlete's mood is not good, the athlete's mind is not on the field and there is chaos and the training is not optimal [11].

An athlete's mood should get more attention from the coach [12]. The coach must be able to distinguish when the athlete is in a positive mood or in a negative mood because, indirectly, this mood can provide good performance and can even give poor performance to athletes, so when the athlete's mood is in a bad condition, it can make the athlete tired, not enthusiastic and will even result in injury to the athlete [13].

Through the training process that has been programmed, continuous and measurable given by the coach to his athletes, an athlete will be able to master all movement techniques that have been trained properly. In addition, the coach must also be able to make the training atmosphere as comfortable as possible for athletes to increase their enthusiasm in training [14]. Because psychologically, with relatively high training, it can indirectly provide an increase in the athlete's physical condition and a significant athlete's physical advantage [15].

The causes of the mood itself also vary. There are factors from the weather, food, home atmosphere and even the surrounding environment [16]. Because everyone has a different heart feeling, an incident that accidentally offends someone can make his mood bad [17]. Likewise with an athlete, for example, when a badminton athlete is training and suddenly his favorite racket breaks and makes him not in the mood for training that day. This requires a coach to provide solutions and indirectly make athletes less moody and down with unnecessary actions [18].

Mood is very important to the athlete for two reasons. First, it has been established that certain mood patterns are very beneficial for athletes' performance in training. For example, performance is successful if the athlete's mood is positive with an above-average strength score of that athlete, and the athlete's negative mood score is below average. Second, mood is a very common and very important self-regulation process in the individual daily life of an athlete. By understanding the nature of an athlete's mood, it may be possible to help athletes achieve maximum performance [19].

One form of improving the mood of athletes that we often read about is by implementing Progressive Muscle Relaxation (PMR) and Autogenic Relaxation (AGR) programs. PMR is a relaxation therapy using tightening and relaxing movements of the muscles in certain body parts given to athletes with physical disorders due to illness, or functionally in the form of decreased daily activities and insomnia [20]. However, AGR is an exercise with more emphasis on a calm and comfortable mind [19].

Sleep is one of the PMR programs that is seen as very important for recovery for athletes in the game, and muscle relaxation. This is a relaxation strategy to compensate for the psychological (cognitive) and physical (somatic) stressors experienced by athletes. There is some evidence for the use of PMR in the general population as a moderately effective treatment for sleep problems. But there is little evidence supporting the use of PMR for athletes [21]. The PMR technique has been used by experts since the early 1920s. PMR is used as a recovery process (managing stress, reducing tension and anxiety) [22].

Recovery is defined as the rebuilding of psychological and physiological resources to enable future use [23]. These different performance contexts involve different mental and physical stresses in each athlete's training. This form of PMR exercise is also believed to affect important organs in the body such as the 
hypothalamic-pituitary-adrenal (HPA) axis, the secretion of the stress hormone cortisol, especially activated when the body responds to stress [24]. Recovery process for training and performance standards must be maintained [25]. The mood of an athlete can last in two periods of time, namely in the short term and in the long term [26].

\section{Materials and Methods}

The use of this research design is adjusted to the research aspects and the main problem to be disclosed. On this basis, the design used in this study is a pretest-posttest control group design, which is a design that has a pretest before being treated. Thus, the results of the treatment can be known more accurately, because it can be compared with the situation before being treated.

Tabel 1. Pretest-posttest control group design

\begin{tabular}{cccc}
\hline Group & Pretest & Treatment & Posttest \\
\hline $\begin{array}{c}\text { Experiment } \\
\text { (PMR) }\end{array}$ & $\mathrm{O}_{1}$ & $\mathrm{X}_{1}$ & $\mathrm{O}_{2}$ \\
\hline $\begin{array}{c}\text { Control } \\
\text { (AGR) }\end{array}$ & $\mathrm{O}_{3}$ & $\mathrm{X}_{2}$ & $\mathrm{O}_{4}$ \\
\hline
\end{tabular}

\subsection{Participants}

The participants were high jump beginner athletes with an average age of 17-20 years. The total participants were 38 people. Then, a random method is used, and the sample was divided into 2 groups (PMR and AGR). A total of 20 samples were in the PMR group and 18 samples were in the AGR group. Prior to the implementation of the study, each sample was given an approval sheet to be a sample in the research to be carried out.

\subsection{Instrument}

The instrument that will be used in data collection uses the Mood State Scale [27], [28]. Respondents were faced on a five-point scale $(1=$ not at all, $2=$ a little, $3=$ moderate, 4 = quite a bit, $5=$ very).

\subsection{Research Procedure}

The study was conducted on beginner high jump athletes. The research process was carried out separately between the PMR and AGR groups. This was done to reduce the occurrence of program and data confusion in this study. The research was carried out for 9 meetings.

Basically, AGR is a program that pays more attention to the state of mind, soul and feelings. By imagining such a beauty, a calm atmosphere, and the rhythm that follows. However, PMR is a form of relaxation that emphasizes more on the muscles in a person's body [19]. The success in this study lies in the focus of the sample and also the instructions given by the trainers/instructors.

Prior to implementing the treatment program (PMR and AGR), each sample was given an initial questionnaire (mood states). Before filling out the questionnaire (pretest), the sample was asked to jump on the high jump field. After that, the sample was asked to fill out the test questionnaire that had been provided. In the instructions for filling out the questionnaire, the sample was emphasized to express his state/mood while doing the high jump. Filling out the questionnaire is in a room that has a temperature of $25-30^{\circ} \mathrm{C}$. After completing the initial questionnaire, each group carried out the program that had been given. Exercise each session is done 30-60 minutes. After the program (PMR and AGR) was completed, the sample was directed to perform high jump exercises. Practice starts at the basic level to a higher level. Each group carried out the series of activities for 9 meetings. After all programs were completed, the sample was asked to complete a questionnaire (posttest). The questionnaires were administered to the same group, but participants were separated from each other (PMR and AGR) to avoid interaction and possible influence on each other [19].

\subsection{Analysis}

The data is calculated to see the distribution of values in each program and look for the minimum, maximum and average values. In the next stage, calculations are carried out to see the normality and homogeneity of each data. The final calculation will calculate the N-Gain Score in the PMR and AGR groups. This calculation aims to test the effectiveness of the use of a particular method or treatment in a one group pretest-posttest design study. The $\mathrm{N}$-Gain score test was carried out by calculating the difference between the pretest and posttest scores. By knowing the N-Gain, we can find out whether the use or application of a certain method can be said to be effective or not. And the last calculation in this study is to do the Independent Sample $t$ Test of the N-Gain value. Test Independent Sample $t$ Test is used to test whether or not there is a difference in the average value (score) of two groups of data that are not paired with each other. The type of data used in the Independent Sample t Test is generally in the form of interval or ratio scale data.

\section{Result}

The results of the research that has been carried out by implementing the PMR and AGR programs for each group and carried out for 9 meetings with the average age of the participants are 17-20 years. Table 2 shows the results of the $\mathrm{N}$-gain score test calculation. It shows that the average $\mathrm{N}$-gain score for the PMR group is 47.8659 or $48 \%$ is included in the less effective category with a minimum $\mathrm{N}$-gain score of $4.35 \%$ and a maximum of $70.37 \%$. Meanwhile, the average N-Gain score for the AGR group is 22.5613 or $23 \%$, which is included in the ineffective category with a minimum N-gain score of 3.33\% and a maximum of $40.91 \%$. 
Table 2. Description of PMR and AGR hasil results

\begin{tabular}{|c|c|c|c|c|c|}
\hline \multicolumn{6}{|c|}{ Descriptives } \\
\hline \multicolumn{4}{|c|}{ Class } & \multirow{2}{*}{$\begin{array}{l}\text { Statistic } \\
47.8659\end{array}$} & \multirow{2}{*}{$\begin{array}{c}\text { Std. Error } \\
3.29730\end{array}$} \\
\hline \multirow{26}{*}{ NGain_Percent } & \multirow{13}{*}{ PMR } & Mean & & & \\
\hline & & \multirow{2}{*}{ 95\% Confidence Interval for Mean- } & Lower Bound & 40.9385 & \\
\hline & & & Upper Bound & 54.7933 & \\
\hline & & \multicolumn{2}{|c|}{ 5\% Trimmed Mean } & 49.0333 & \\
\hline & & \multicolumn{2}{|l|}{ Median } & 48.0000 & \\
\hline & & \multicolumn{2}{|l|}{ Variance } & 206.572 & \\
\hline & & \multicolumn{2}{|l|}{ Std. Deviation } & 14.37261 & \\
\hline & & \multicolumn{2}{|l|}{ Minimum } & 4.35 & \\
\hline & & \multicolumn{2}{|l|}{ Maximum } & 70.37 & \\
\hline & & \multicolumn{2}{|l|}{ Range } & 66.02 & \\
\hline & & \multicolumn{2}{|c|}{ Interquartile Range } & 15.56 & \\
\hline & & \multicolumn{2}{|l|}{ Skewness } & -1.310 & .524 \\
\hline & & \multicolumn{2}{|l|}{ Kurtosis } & 3.879 & 1.014 \\
\hline & \multirow{13}{*}{ AGR } & \multicolumn{2}{|l|}{ Mean } & 22.5613 & 2.44071 \\
\hline & & \multirow{2}{*}{ 95\% Confidence Interval for Mean } & Lower Bound & 17.4336 & \\
\hline & & & Upper Bound & 27.6890 & \\
\hline & & \multicolumn{2}{|l|}{ 5\% Trimmed Mean } & 22.6102 & \\
\hline & & \multicolumn{2}{|l|}{ Median } & 21.6216 & \\
\hline & & \multicolumn{2}{|l|}{ Variance } & 113.184 & \\
\hline & & \multicolumn{2}{|l|}{ Std. Deviation } & 10.63882 & \\
\hline & & \multicolumn{2}{|l|}{ Minimum } & 3.33 & \\
\hline & & \multicolumn{2}{|l|}{ Maximum } & 40.91 & \\
\hline & & \multicolumn{2}{|l|}{ Range } & 37.58 & \\
\hline & & \multicolumn{2}{|l|}{ Interquartile Range } & 19.05 & \\
\hline & & \multicolumn{2}{|l|}{ Skewness } & .228 & .524 \\
\hline & & \multicolumn{2}{|l|}{ Kurtosis } & -.697 & 1.014 \\
\hline
\end{tabular}

Table 3. Normality calculation results

\begin{tabular}{|c|c|c|c|c|c|c|c|}
\hline \multicolumn{8}{|c|}{ Tests of Normality } \\
\hline & \multirow{2}{*}{ Class } & \multicolumn{3}{|c|}{ Kolmogorov-Smirnov ${ }^{a}$} & \multicolumn{3}{|c|}{ Shapiro-Wilk } \\
\hline & & Statistic & Df & Sig. & Statistic & df & Sig. \\
\hline \multirow{2}{*}{ NGain_Percent } & PMR & .165 & 19 & .184 & .894 & 19 & .038 \\
\hline & Control & .118 & 19 & $.200^{*}$ & .961 & 19 & .594 \\
\hline This is a lower bou & e true sign & & & & & & \\
\hline Lilliefors Significa & rection & & & & & & \\
\hline
\end{tabular}

Thus, from the results of the calculations in table 2 , it can be concluded that the use of the PMR method is less effective in improving the mood of high jump beginner athletes. Meanwhile, the use of the AGR method is also less effective in improving the mood of the novice high jump athletes. Thus, the requirements for using the independent sample $\mathrm{t}$ test for the $\mathrm{N}$-gain score are met and can be continued on the Independent Samples t Test.
Based on table 3 of the Test of Normality output above, it is known that the significance value (Sig.) in the Kolmogorov-Smirnov test for the N-Gain Percent value in the PMR group is 0.184 and the AGR group is 0.200 . Since the value of Sig. both groups are greater than 0.05 , it can be said that the data is normally distributed. Thus, the requirements for using the independent sample $t$ test for the N-gain score are met and can be continued on the Independent Samples Test. 
Table 4. Calculation results of N_Gain

\begin{tabular}{lccccc}
\hline & \multicolumn{5}{c}{ Group Statistics } \\
\hline \multirow{2}{*}{ NGain_Percent } & Class & N & Mean & Std. Deviation & Std. Error Mean \\
\cline { 2 - 6 } & Experiment & 19 & 47.8659 & 14.37261 & 3.29730 \\
\hline
\end{tabular}

Table 5. Independent Samples Test

\begin{tabular}{|c|c|c|c|c|c|c|c|c|c|c|}
\hline \multicolumn{11}{|c|}{ Independent Samples Test } \\
\hline & & \multicolumn{2}{|c|}{$\begin{array}{c}\text { Levene's Test } \\
\text { for Equality of } \\
\text { Variances }\end{array}$} & \multicolumn{7}{|c|}{ t-test for Equality of Means } \\
\hline & & \multirow[t]{2}{*}{$\mathbf{F}$} & \multirow[t]{2}{*}{ Sig. } & \multirow[t]{2}{*}{$\mathbf{T}$} & \multirow[t]{2}{*}{ df } & \multirow{2}{*}{$\begin{array}{c}\text { Sig. } \\
\text { (2-tailed) }\end{array}$} & \multirow{2}{*}{$\begin{array}{c}\text { Mean } \\
\text { Difference }\end{array}$} & \multirow{2}{*}{$\begin{array}{l}\text { Std. Error } \\
\text { Difference }\end{array}$} & \multicolumn{2}{|c|}{$\begin{array}{c}95 \% \text { Confidence Interval } \\
\text { of the Difference }\end{array}$} \\
\hline & & & & & & & & & Lower & Upper \\
\hline \multirow{2}{*}{$\begin{array}{l}\text { NGain_ } \\
\text { Percent }\end{array}$} & $\begin{array}{c}\text { Equal variances } \\
\text { assumed }\end{array}$ & .403 & .530 & 6.168 & 36 & .000 & 25.30460 & 4.10235 & 16.98465 & 33.62455 \\
\hline & $\begin{array}{c}\text { Equal variances not } \\
\text { assumed }\end{array}$ & & & 6.168 & 33.171 & .000 & 25.30460 & 4.10235 & 16.95993 & 33.64927 \\
\hline
\end{tabular}

Refers to the category of interpretation of the effectiveness of N-Gain [29]. Based on table 4 of the output group statistics above, it is known that the average value (Mean) of NGain_Percent for the PMRsebasar group is 47.8659 or if it is rounded it becomes $48 \%$. Based on the category of interpretation of the effectiveness of the NGain value (\%), it can be concluded that the use of the PMR method is less effective in improving the mood states of high jump beginners.

Meanwhile, based on the output group statistics table above, it is known that the average value (Mean) of NGain_Percent for the AGR group is 22.5613 or if rounded it becomes $23 \%$. Based on the category of interpretation of the effectiveness of the NGain value (\%), it can be concluded that the use of the AGR method is not effective in improving the mood states of beginner high jump athletes.

Based on table 5, it is known that the significance value (Sig) on Levene's Test for Equality of Variances is $0.530>$ 0.05 , so it can be concluded that the variance of the $\mathrm{N}$-Gain data (\%) for the PMR and AGR groups is the same. Thus, the independent sample $t$ test for the $\mathrm{N}$-Gain score is guided by the Sig value. contained in the table Equal Variances assumed.

Based on the Independent Samples Test output table, it is known that the value of Sig (2-tailed) is $0.000<0.05$. Thus, it can be concluded that there is a significant (significant) difference in effectiveness between the use of the PMR method and AGR to improve mood states.

\section{Discussions}

The primary function of relaxation is to overcome competitive anxiety and promote recovery, but relaxation has also been reported to be used to treat anxiety associated with athlete states [30]. More physical (for example, muscle relaxation) and the type of mental relaxation are used to deal with competitive anxiety. While mental (for example, meditation) is also more than the type of physical relaxation used in relation to dealing with anxiety.

The results of the research that have been carried out state that, in fact, there are differences in the results of the exercise between the PMR and AGR programs. However, these results are still considered less effective in improving the mood state of beginner athletes in the high jump. This is actually slightly different from the results of previous studies, which stated that there was a difference between PMR and AGR [19], [31]. The results of this study more or less have different characteristics in their application. The research carried out more targeting individual or individual sports, while previous research was related to team sports. Actually, the PMR training is a measurable and systematic technique in order to overcome and relax the muscles [32]. Meanwhile, in another study, it was explained that there was no effect of progressive muscle relaxation exercises on the respondent's stress value (p value 0.363 ). [33].

However, in AGR, a form of exercise aims to improve sports performance. This form of exercise can be done by taking a position when the situation allows the practice to take place safely and well, such as a clean, comfortable and free from crowds [34]. Because this situation can interfere with the athlete's concentration during training. There are also relaxation exercises with this AGR technique such as: 1) Listening to your favorite song to please the heart and calm the soul; 2) relax somewhere that makes him comfortable. Exercises like this are carried out during practice or before a match that makes the athlete focus on his activities. In the AGR group, based on the category of interpretation of the effectiveness of the use of this method, it is also not effective in improving the mood of the high jump beginner athletes. 
It is possible that there is no relationship or influence due to the intensity and duration of exercise that are not optimal for athletes. In addition, novice athletes still do not know how to use the PMR and AGR methods, so they cannot maximize their training process. Participants can interact with each other and generate mood benefits for training and as much as possible the athletes and coaches make the training atmosphere as comfortable as possible [35].

It is very important that this exercise program runs optimally, because with relaxation the athlete feels relaxed, has an impact on performance, concentration, and pleasure, and the effect is positive (impacts on the results of relaxation exercises) [30].

This exercise is very necessary for athletes because anxiety as a negative emotion can affect perceptions in sports, where most athletes consider anxiety to weaken performance and can result in decreased performance [36]. Meanwhile, in postoperative women, PMR is one of the most effective techniques to use in order to obtain a deep level of relaxation [37]. In burn athletes, this relaxation exercise is a fairly effective way to reduce anxiety and stress levels [38].

This progressive muscle relaxation exercise has a positive effect on a very positive mood in Malaysia and Iran [39]. Athletes in these countries prefer to use this relaxation training technique because their muscles are more relaxed and their minds are more open. As a result of this, the training of athletes in Malaysia and Iran has significantly increased [39].

PMR is a very effective tool for regulating the state of the athlete's mood. Not only mood, but also anxiety and stress can be regulated through this PMR. For example, volleyball players were randomized into experimental groups to measure anxiety and showed decreased anxiety results [21]. The relaxation exercise shows that the technique can also provide an alternative offer (reducing addiction to nicotine, alcoholic beverages and drugs) that is very easy to learn. [40]

\section{Conclusion}

The results of this study can be concluded that the effect of PMR and AGR to improve mood in high jump beginner athletes has a difference in doing relaxation exercises. Relaxation exercises are used to improve the athlete's mood. This method can also be applied as a form of warm-up exercise or by relaxing the muscles in the body. The results of these exercises are expected to have an impact on mood and reduce stress and muscle anxiety. Athletes can start training from the lower body and work their way up, or vice versa. That way athletes can feel the order that is very easy to follow. This progressive muscle relaxation exercise has a positive effect on very positive moods in Malaysia and Iran. This relaxation exercise technique is indeed very widely used by athletes in various countries. Therefore, athletes should record the duration of this exercise as an effective tool for regulating mood states. Not only mood, but also anxiety and stress can be managed through this exercise.

Recommendations for further researchers are that this study should be carried out for 9 meetings and was less effective or less significant in improving mood states for novice high jump athletes. Therefore, further research is recommended to implement the PMR and AGR programs with a longer period of time. Then this PMR and AGR may have an influence on other variables. And the last is recommended for PMR and AGR programs in individual sports and team sports to determine the level of effectiveness.

\section{Acknowledgements}

The authors would like to thank Lembaga Penelitian dan Pengabdian Masyarakat Universitas Negeri Padang for funding this work with a contract number: 752/UN35.13/LT/2021.

\section{REFERENCES}

[1] A. Andrade, G. G. Bevilacqua, D. R. Coimbra, F. S. Pereira, and R. Brandt, "Sleep quality, mood and performance: A study of elite Brazilian volleyball athletes," J. Sport. Sci. Med., vol. 15, no. 4, pp. 601-605, 2016.

[2] M. Turgut, Y. Soylu, and S. N. Metin, "Physical activity, night eating, and mood state profiles of athletes during the COVID-19 pandemic," Prog. Nutr., vol. 22, no. 6, 2020, doi: 10.23751/pn.v22i2-S.10567.

[3] A. Andrade, C. K. Correia, W. M. Da Cruz, and G. G. Bevilacqua, "Acute Effect of Exergames on Children's Mood States during Physical Education Classes," Games Health J., vol. 8, no. 4, pp. 250-256, 2019, doi: 10.1089/g4h.2018.0083.

[4] N. J. Ahmed, A. S. Alrawili, and F. Z. Alkhawaja, "Mood and Anxiety Disorders among the Public," J. Pharm. Res. Int., vol. 32, no. 7, pp. 72-78, 2020, doi: 10.9734/jpri/2020/v32i 730462 .

[5] P. Terry, "The Efficacy of Mood State Profiling with Elite Performers: A Review and Synthesis," Sport Psychol., vol. 9, no. 3, pp. 309-324, 2016, doi: 10.1123/tsp.9.3.309.

[6] I. Kontaris, B. S. East, and D. A. Wilson, "Behavioral and Neurobiological Convergence of Odor, Mood and Emotion: A Review," Front. Behav. Neurosci., vol. 14, no. March, pp. 1-15, 2020, doi: 10.3389/fnbeh.2020.00035.

[7] S. Darvishi, A. Marati, and B. Amirpour, "Effectiveness of emotional intelligence on mood profile in female student athletes," J. Res. Heal., vol. 5, no. 1, pp. 21-27, 2015.

[8] M. Johansson, P. Hassmén, and J. Jouper, “Acute Effects of 
Qigong Exercise on Mood and Anxiety," Int. J. Stress Manag., vol. 15, no. 2, pp. 199-207, 2008, doi: 10.1037/1072-5245.15.2.199.

[9] R. Köhler-Ryan, “The Hour of Woman' and Edith Stein: Catholic New Feminist Responses to Essentialism," Religions, vol. 11, no. 6, 2020, doi: 10.3390/rel11060271.

[10] A. M. Smith, M. J. Stuart, D. M. Wiese-Bjornstal, E. K. Milliner, W. M. O'fallon, and C. S. Crowson, "Competitive Athletes: Preinjury and Postinjury Mood State and Self-Esteem," Mayo Clin. Proc., vol. 68, no. 10, pp. 939947, 1993, doi: 10.1016/S0025-6196(12)62265-4.

[11] H. Gustafsson, J. D. DeFreese, and D. J. Madigan, "Athlete burnout: review and recommendations," Curr. Opin. Psychol., vol. 16, pp. 109-113, 2017, doi: 10.1016/j.copsyc.2017.05.002.

[12] M. Lehmann, C. Foster, U. Gastmann, H. Keizer, and J. M. Steinacker, Overload, Performance Incompetence, and Regeneration in Sport. New York, Boston, Dordrecht, London, Moscow: Kluwer Academic/Plenum Publishers, 1999.

[13] S. Kölling, R. Duffield, D. Erlacher, R. Venter, and S. L. Halson, "Sleep-related issues for recovery and performance in athletes," Int. J. Sports Physiol. Perform., vol. 14, no. 2, pp. 144-148, 2019, doi: 10.1123/ijspp.2017-0746.

[14] M. Malekshahi, B. Abdoli, A. Asefirad, and F. Mohammadi, "The comparison the effect of mediate and high intensities of aerobic exercise on non athlete girl Students' Mood States," Procedia - Soc. Behav. Sci., vol. 15, pp. 1887-1891, 2011, doi: 10.1016/j.sbspro.2011.04.021.

[15] P. Ford et al., "The Long-Term Athlete Development model: Physiological evidence and application," J. Sports Sci., vol. 29, no. 4, pp. 389-402, 2011, doi: 10.1080/02640414.2010 .536849 .

[16] J. L. O. Bueno and M. A. Di Bonifácio, "Alterações de estados de ânimo presentes em atletas de voleibol, avaliados em fases do campeonato," Psicol. em Estud., vol. 12, no. 1, pp. 179-184, 2007, doi: 10.1590/s1413-737220070001000 21.

[17] R. L. Vancini et al., "Quality of life, depression, anxiety symptoms and mood state of wheelchair athletes and non-athletes: A preliminary study," Front. Psychol., vol. 10, no. AUG, pp. 1-7, 2019, doi: 10.3389/fpsyg.2019.01848.

[18] A. Andrade, G. Bevilacqua, P. Casagrande, R. Brandt, and D. Coimbra, "Sleep quality associated with mood in elite athletes," Phys. Sportsmed., vol. 47, no. 3, pp. 312-317, 2019, doi: 10.1080/00913847.2018.1553467.

[19] H. A. Hashim, H. Hanafi, and A. Yusof, "The effects of progressive muscle relaxation and autogenic relaxation on young soccer players' mood states," Asian J. Sports Med., vol. 2, no. 2, pp. 99-105, 2011, doi: 10.5812/asjsm.34786.

[20] E. E. Labbe', “Treatment of Childhood Migraine With Autogenic Training and Skin Temperature Biofeedback: A Component Analysis," Headache J. Head Face Pain, vol. 35, no. 1, pp. 10-13, 1995, doi: 10.1111/j.1526-4610.1995.hed3501010.x.

[21] K. A. Vento, "The Effects of Progressive Muscle Relaxation on the Subjective Well-Being of Collegiate
Athletes," ProQuest Diss. Theses, no. May, p. 63, 2017.

[22] Cheung YL, M. A, and C. AM, "The effect of progressive muscle relaxation training on anxiety and quality of life after stoma surgery in colorectal cancer patients," Psychooncology., vol. 12, no. 3, pp. 254-266, 2003.

[23] N. Kajimura et al., "A polysomnographic study of sleep patterns in normal humans with low- or high-anxiety personality traits," Psychiatry Clin. Neurosci., vol. 52, no. 3, pp. 317-320, 1998, doi: 10.1046/j.1440-1819.1998.00401. $\mathrm{x}$.

[24] D. B. Miller and J. P. O'Callaghan, "Neuroendocrine aspects of the response to stress," Metabolism., vol. 51, no. 6 SUPPL. 1, pp. 5-10, 2002, doi: 10.1053/meta.2002.3318 4.

[25] J. Beckmann and M. Kellmann, "Self-Regulation and Recovery: Approaching an Understanding of the Process of Recovery from Stress," Psychol. Rep., vol. 95, pp. 11351153, 2004, doi: 10.2466/pr0.95.3f.1135-1153.

[26] A. Urhausen, H. H. W. Gabriel, B. Weiler, and W. Kindermann, "Ergometric and psychological findings during overtraining: A long-term follow-up study in endurance athletes," Int. J. Sports Med., vol. 19, no. 2, pp. 114-120, 1998, doi: 10.1055/s-2007-971892.

[27] S. H. Bolanos, D. A. Khan, M. Hanczyc, M. S. Bauer, N. Dhanani, and E. S. Brown, "Assessment of mood states in patients receiving long-term corticosteroid therapy and in controls with patient-rated and clinician-rated scales," Ann. Allergy, Asthma Immunol., vol. 92, no. 5, pp. 500-505, 2004, doi: 10.1016/S1081-1206(10)61756-5.

[28] K. Yoshihara, T. Hiramoto, N. Sudo, and C. Kubo, "Profile of mood states and stress-related biochemical indices in long-term yoga practitioners," Biopsychosoc. Med., vol. 5, no. June, 2011, doi: 10.1186/1751-0759-5-6.

[29] R. R. Hake, Analyzing Change/Gain Score, 2nd ed. Indiana, Amerika Serikat: Indiana: Indiana University, 1999.

[30] K. Kudlackova, D. W. Eccles, and K. Dieffenbach, "Use of relaxation skills in differentially skilled athletes," Psychol. Sport Exerc., vol. 14, no. 4, pp. 468-475, 2013, doi: 10.1016/j.psychsport.2013.01.007.

[31] L. M. Saleh, S. S. Russeng, Awaluddin, and M. R. Rahim, "The effect of progressive muscle relaxation on decreasing work stress in air traffic controller," Enferm Clin, vol. 30, no. 4, pp. 231-235, 2020, doi: 10.1016/j.enfcli.2019.10.08 0 .

[32] A. Singh, T. Singh, and H. Singh, "Autogenic Training and Progressive Muscle Relaxation Interventions: Effects on Mental Skills of Females," Eur. J. Phys. Educ. Sport Sci., vol. 5, no. 1, pp. 134-141, 2018, doi:10.5281/zenodo. 1598 556.

[33] S. Wicaturatmashudi, I. Erman, and Azwaldi, "The effect of progressive muscle relaxation on stress in diabetes mellitus patient," Enferm Clin, vol. 30 Suppl, no. 3, pp. 104-107, 2020, doi: 10.1016/j.enfcli.2020.02.002.

[34] P. Nicassio and R. Bootzin, "A comparison of progressive relaxation and autogenic training as treatments for insomnia," J. Abnorm. Psychol., vol. 83, no. 3, pp. 253-260, 1974, doi: 10.1037/h0036729. 
[35] R. R. Yeung, "The acute effects of exercise on mood state," J. Psychosom. Res., vol. 40, no. 2, pp. 123-141, 1996, doi: 10.1016/0022-3999(95)00554-4.

[36] V. A. Parnabas, Y. Mahamood, J. Parnabas, and N. M. Abdullah, "The Relationship between Relaxation Techniques and Sport Performance," Universal Journal of Psychology, vol. 2, no. 3, pp. 108-112, 2014, doi: 10.13189/ujp.2014.020302.

[37] [37] R. M. Essa, N. I. A. A. Ismail, and N. I. Hassan, "Effect of progressive muscle relaxation technique on stress, anxiety, and depression after hysterectomy," J. Nurs. Educ. Pract., vol. 7, no. 7, p. 77, 2017, doi: 10.5430/jnep.v7n7p77.

[38] M. Harorani, F. Davodabady, B. Masmouei, and N. Barati,
"The effect of progressive muscle relaxation on anxiety and sleep quality in burn patients: A randomized clinical trial," Burns, vol. 46, no. 5, pp. 1107-1113, 2020, doi: 10.1016/j.burns.2019.11.021.

[39] T. Bagherpour, H. A. Hashim, S. Saha, and A. K. Ghosh, "Comparison of long -Term Effects of Internal Imagery and Progressive Muscle Relaxation on Brunel Mood among Malaysian and Iranian Taekwondo athletes," Int. Conf. Educ. Manag. Innov., vol. 30, no. 30, pp. 225-230, 2012.

[40] D. Vancampfort et al., "Effects of progressive muscle relaxation on state anxiety and subjective well-being in people with schizophrenia: A randomized controlled trial," Clin. Rehabil., vol. 25, no. 6, pp. 567-575, 2011, doi: $10.1177 / 0269215510395633$ 